\title{
The Impact of Emerging Regulatory Regime on the Private Health Insurance Industry in Ghana
}

\author{
Richmond Bansah ${ }^{1, *}$, Augustina Sidza ${ }^{1}$, Victoria Akita ${ }^{2}$ \\ ${ }^{1}$ Finance Directorate, Accra Technical University, Accra, Ghana \\ ${ }^{2}$ Department of Accounting \& Finance, Kwame Nkrumah University of Science and Technology, Kumasi, Ghana
}

Email address:

richiebansah24@gmail.com (R. Bansah)

${ }^{*}$ Corresponding author

To cite this article:

Richmond Bansah, Augustina Sidza, Victoria Akita. The Impact of Emerging Regulatory Regime on the Private Health Insurance Industry in Ghana. Journal of Finance and Accounting. Vol. 9, No. 5, 2021, pp. 200-206. doi: 10.11648/j.jfa.20210905.13

Received: August 31, 2021; Accepted: September 28, 2021; Published: October 15, 2021

\begin{abstract}
The study sought to examine how the current regulatory reforms in the insurance industry impact the services of insurance schemes in Ghana. The study used primary data comprising 60 employees in management positions in private health insurance companies in Ghana, and 5 personnel from the National Health Insurance Authority, the regulator. The employees were selected using purposive sampling technique, while the private health insurance companies that participated in the study were chosen using simple random sampling technique. Descriptive research, mean and standard deviation, as well as inferential statistics of ordinary simple linear regression analysis were used to analyze the data of the study. The results of the study revealed that the main reason for the current insurance regulatory framework in Ghana is to ensure safety and soundness of insurers; offer protection to consumers; bring sanity into insurance industry; promote best practices; mitigate industry associated risks, and to safeguard the interest of all stakeholders for socio-economic development. The findings of the study also revealed that the current insurance regulatory measures were established to manage systemic risks and market failures. The result of the study also revealed that the regulatory framework has both positive and negative impact on insurance companies' activities in Ghana. Moreover, the findings of the study revealed that the regulatory challenges facing the insurers are logistical, education and training, human resource, legislative, and economic or financial ones. The results of the ordinary simple linear regression revealed that the regulatory challenges faced by insurers have a significant negative impact on the insurers' overall satisfaction with the regulatory framework. Given these findings of the study, implication and recommendations are highlighted for policymakers, regulators and researchers.
\end{abstract}

Keywords: Regulatory Reforms, Regulator, Private Health Insurance, Regulatory Framework, Insurance

\section{Introduction}

\subsection{Background to the Report}

Insurance is a pooling of risks by individuals, where part of the payment of the many is used to pay to the few who suffer losses [1, 2] Anderson and Brown [3] posited that under any proper insurance arrangement, every contract client (policyholder) indirectly pools his risk with all other policyholders. Insurance is intended to fulfill the monetary well-being of an individual, company or other entity in the case of unexpected losses. Some forms of insurance are obligatory while others are optional [4].

Companies that develop and sell insurance policies are regulated by laws and other regulatory policies set by the States within which they operate. With the growth in the insurance industry, States started creating regulatory bodies to have oversight responsibility of the industry. This responsibility spans from granting licenses to an insurance company, agents etc., ensuring that solvency of the insurers are maintained at all times, ensuring policyholders and stakeholders are treated fairly and to prohibit deceptive and dubious activities.

In Ghana, creation of a regulatory body led to the passage of the insurance law 1989 (PNDC Law 227). This paved way for 
the establishment of the National Insurance Commission (NIC) which currently operates under the Insurance Act, 2006 (Act 724). The NIC oversees activities of the life, non-life, reinsurers and brokerage companies. Within the past two-and-half decades, the insurance sector has experienced some regulative changes including the segregation of life and non-life businesses since 2006, premium credit abolition in the market in 2014 with the caption "no premium no cover," and increase in minimum capital of insurers by the close of 2015 .

Subsequently, the passing of another law, The National Health Insurance Act, 2003 (Act 650) established and charged the National Health Insurance Authority among other functions, to ensure that all resident have access to basic healthcare services under the operation of a National Health Insurance Scheme. The National Health Insurance Authority (NHIA) is also mandated to regulate Private Health Insurance Schemes (PHIS) in Ghana. The legislation set up two (2) forms of private health insurance schemes: The Private Mutual Health Insurance Scheme (PMHIS) operated exclusively for the advantage of its members such as communal, religious and occupational/ carrier based groups etc. and Private Commercial Health Insurance Scheme (PCHIS) which are owned and managed on profit- oriented basis by shareholders and dependent on business values. The law was amended to the current act, the National Health Insurance Act, 2012 (Act 852) to allow an effective administration and a more robust regulation and supervision.

In 2008, the National Pensions Act (Act 766) was passed and this led to the creation of the National Pensions Regulatory Authority to oversee the implementation of the 3-tier Pension Scheme and ensure efficient management of all pensions in the country. In 2011, accompanying regulations, the Basic National Social Security Scheme, (L. I 1989) and the Occupational and Personal Social Security Scheme (General) Regulations (L. I 1990) were passed to augment the Act 766 for effective implementation.

Regulatory reforms are designed to influence stakeholders' economic activities in ways that will enhance economic welfare [5]. The level of understanding of insurance coverage in Ghana and West Africa as a whole has risen in recent years, though not promising, the latest observations suggest insurance awareness is rising but very sluggish [6].

According to the July edition of the Business and Financial Times [7], insurance business is among the few developed businesses in Ghana. Despite its low penetration, the sector is continuously generating substantial profit. It plays a vital role within the economy by permitting individuals and corporate entities to transfer risk for a premium. Improvement in the stabilization of financial markets is dependent on a healthy and well-developed insurance industry. In addition, the insurance sector safeguards individuals and corporate entities from losses emanating from unforeseen natural disasters.

\subsection{Problem Statement}

Insurers are without doubt a significant component of the financial sector. They are systemically important for the economy because they provide an essential economic function. Major roles such as financial intermediaries and financial market investors are played by large insurance companies. They also play a major economic role by enabling companies and households manage their financial risks. Regulating insurers makes way for prudential rules that prevent the entry of entities with doubtful reputation or weak financial capacity and also control risks associated with financial, operational and governance activities of existing companies. According to Hutter et al. [8], State regulation through the application of the law, commonly known as command-and-control regulation, is probably the best known approach. However, it is the least preferred by businesses and per regulation theorists, not always productive. Advancing the regulation of systemic risk in insurance without a clear understanding of the foundations and transmission channels could end up not addressing the right parts as well as not using the right tools and ultimately not mitigating the risks. Notably, given the different economic and financial role of capital compared with financial sectors like banking, it is not evident that capital surcharges would be the preferred instruments in insurance. All policy actions have unintended and potentially undesirable consequences [9].

These issues are fully known to insurance regulators. Time and proper analysis should be given to them to address issues in the right way and sequence. Compliance remains a high concern for insurance companies as the pace and complexity of regulatory change, in addition to increased regulatory scrutiny and enforcement activity have pushed concerns regarding reputation risk to new levels. These companies ought to be able to respond flexibly and speedily to changes in their internal and external environments so as to limit the impacts from potentially expensive business shifts or compliance.

Private health insurance (PHI) schemes generally strive to achieve three main overlapping functions $[10,11]$ the first is to function as a substitute for state-funded health care. PHI may in this case be crucial to certain groups that are excepted from any or all aspects of state coverage, or it may provide an alternative for populations who are permitted to choose between public and private coverage (e.g. higher-income households). Secondly, PHI can serve as co-payment for healthcare services (such as dental care) that are partially covered by the state and this is known as complementary. Finally, PHI could be supplementary that is providing coverage for the services not covered by state insurance and permitting patients to choose their preferred service provider or faster access to services.

In the absence of regulatory interventions in a PHI market, insurers would possibly tend to embrace practices aimed at mitigating their risk to avoid losses, for instance denial of coverage for applicants who have preexisting health conditions [12]. Conversely, overregulation may place tremendous stress on insurers leading to market strangulation (a situation in which insurance companies are unable to operate sustainably hence are compelled to shut down) [13]. It is in this context the study aims at examining the private health insurance industry's emerging regulatory regime and its impact on insurance. 


\subsection{Objectives}

The study specifically sought to:

a. Examine the regulatory measures of the current insurance regulatory reforms in Ghana.

b. Determine the impact of the current regulatory reforms on the activities of the insurance companies in Ghana.

c. Ascertain the regulatory challenges faced by the insurance companies in Ghana.

d. Analyze the impact of the regulatory challenges on insurance companies' overall satisfaction with the regulatory framework.

\section{Literature Review}

Insurance entails pooling of funds from several insured entities (known as exposures) to compensate for the losses that some might suffer. It provides security against the economic impact of an untimely death, health, accidents, and funeral among others [14]. Insurance companies play a vital role in a nation's economic development. One of the major contributions of the industry is the raising of long-term resources, which increases an economy's capacity for long-term investment [15].

\subsection{Theoretical Framework}

\subsubsection{Public Interest Theory}

The public interest theory of regulatory reforms is the theoretical foundation of this research. The public interest theory of regulation generally explains that regulation aims at the protection and benefit of the public as a whole. Although various authors $[16,17]$ have identified public interest theory of regulatory reforms as part of welfare economics, none has been ascribed as the originator of the theory. The public interest theory of regulatory reforms has two main philosophies. The first, embraced by Stigler [18] and Posner [19] explains that regulation aims at the protection and benefit of the public as a whole. The second, established by subsequent academics, defines it as a framework of ideas which suggests that economic regulation should be imposed to maximize social welfare when the market fails.

\subsubsection{Regulatory Restrictions on Public Interest Theory}

The rationale offered for regulatory restrictions under the public interest theory on insurance is that consumer search costs hinder competition and result in excessive prices and profits. Furthermore, consumers can be made susceptible to abusive marketing and claims practices of insurers and agents due to inaccurate consumer information and uneven brokering power between the insurers and consumers.

It can also be argued that it is expensive for insurers to precisely determine consumers' risk characteristics, giving the insurers already in business informational advantage and creating entry barriers to decrease competition.

\subsection{Conceptual Review}

\subsubsection{Evolution of Insurance}

Insurance has a long custom of varied appraisal within the public and political opinion [20]. Across all markets economies, its economic and social value is undisputed. Its technological architecture and actual performance have however attracted numerous complaints and criticism contributing to a significant increase in legal constraints, state legislation and control of the insurance market. Although some of these issues may actually be due to dubious acquisition and claim settlement practices, it is renowned that majority of insurance difficulties cannot be associated within appropriate behavior of insurance firms. Instead, it is insurance itself, this "awkward good" as it has been called [21], which causes many of the problems.

\subsubsection{Life Insurance}

An agreement between a customer (policyholder) and an insurer to compensate a delegated beneficiary upon the death of the insured is referred to as life insurance. Pension savings and health insurance all find their foundation in this form of insurance. Life insurance has the most prospects to gain lower income sections of the population. The biggest share of the life insurance market is in the advanced countries. Market penetration or insurance premiums as a section of GDP are highest in Japan with, 8.26\%, Western Europe, 5.1\% and 4.12\% for North America. For emerging markets, South and East Asian economies lead with $3.77 \%$, Africa and South Africa follows with $3.41 \%$, then Latin America and the Caribbean at $1.01 \%$ and the Middle East and Central Asian economies at $0.47 \%$. (SIGMA edition No. 2/2005, World Insurance in 2004: Growing Premiums and Stronger Balance Sheets.).

\section{Methodology}

\subsection{Research Design}

The study used the triangulation mixed-method research design. The triangulation mixed-method research design is better-known approach to mixed methods [22]. This design was selected in order; to acquire diverse but complimentary information on the same research topic [23] to best understand the research problem, to gather the varying strengths and non-overlapping flaws of quantitative methods (large sample size, trends, generalization) along qualitative approaches (small N, details, in-depth) [24].

\subsection{Population, Sample, Sampling Technique and Instrument}

Population of a study is a whole group for which some information is needed to be determined [25]. For this study, the entire population comprised all insurance companies, both private and public, in Ghana.

The target population is made up the 14 private health insurance schemes in Ghana licensed by the National Health Insurance Authority (NHIA), the regulator under the National Health Insurance Act, 2012 (Act 852) [26] and personnel from the NHIA.

The sample size was determined using the Slovin's sample size determination formula: 


$$
\mathrm{S}=\mathrm{N} / 1+\left(\mathrm{N}+\mathrm{E}^{2}\right)
$$

Where

$\mathrm{SS}=$ required sample size;

$\mathrm{N}=$ total study population (14);

$\mathrm{E}=$ margin error $(5 \%)$.

Sloven's formula was used since that is the most appropriate formula used when nothing is known about the behavior of a study population. In all a sample size of 13 out of the 14 licensed private health insurance companies were selected for the study.

\section{Results and Discussions}

\subsection{Regulatory Measures of the Current Insurance Regulatory Reforms in Ghana}

The participants of the study were asked to indicate, using a scale of 1 to 5 , their level of agreement with the regulatory measures of the current insurance regulatory reforms in Ghana, with 1 being strongly disagree; 2, disagree; 3 , neutral; 4 , agree; and 5 , strongly agree. Table 1 shows the mean and the standard deviation of the participants' responses.

Table 1. Mean and Standard Deviation of the Responses of the Participants on the Regulatory Measures of the Current Insurance Regulatory Reforms in Ghana.

\begin{tabular}{lll}
\hline Regulatory Measures & Mean \\
\hline Powers of granting licenses to companies & 4.47 \\
Licensing of intermediaries & 4.03 \\
Powers to withdraw authorization/license & 4.812 & 0.688 \\
Evaluate quality of governance structure in companies & 0.843 & 4.02 \\
Evaluate quality of management structure in companies & 3.82 \\
Evaluate performance of governing body of company & 1.049 \\
Evaluate performance of management team of company & 0.910 \\
Examination of insurer's books and records & 1.186 \\
Require insurers to maintain acceptable financial records & 0.810 & 3.95 \\
Evaluate the quality of insurer's assets & 0.497 & 4.23 \\
Approve insurer's products & 4.42 \\
Educate consumers/stakeholders about insurance matters & 4.03 \\
Make reliable information on insurers available publicly & 4.02 \\
\hline
\end{tabular}

Source: Author's Fieldwork (2020).

As shown in the table above, the participants of the study indicated that under the current insurance regulatory reforms, the National Health Insurance Authority (NHIA), the regulator of the private health insurance schemes in Ghana, has been given the power to grant licenses to the private health insurance companies $(\mathrm{M}=4.47, \mathrm{SD}=.812)$, license intermediaries of health insurance companies $(\mathrm{M}=4.03$, $\mathrm{SD}=.688)$, and withdraw authorization/license $(\mathrm{M}=4.03$, $\mathrm{SD}=.843$ ). The participants of the study also indicated that the NHIA has the power to evaluate the quality of governance structure $(\mathrm{M}=4.02, \mathrm{SD}=.873)$, evaluate the quality of management structure $(\mathrm{M}=3.82, \mathrm{SD}=1.049)$, evaluate the performance of the governing body $(\mathrm{M}=3.95$, $\mathrm{SD}=.910$ ) and also to evaluate the performance of the management team of the private health insurance companies $(\mathrm{M}=3.13, \mathrm{SD}=1.186)$.

Meanwhile, the participants' responses, as presented in the table, indicated that the NHIA has the power to examine the books and records of the private health insurance companies $(\mathrm{M}=4.23, \mathrm{SD}=.810)$, require them to maintain acceptable financial records $(\mathrm{M}=4.42, \mathrm{SD}=.497)$, evaluate the quality of their assets $(M=4.03, S D=.843)$, and to approve their products $(\mathrm{M}=4.02, \mathrm{SD}=.792)$. The participants of the study also indicated that the NHIA has been given the power to educate consumers or stakeholders about insurance matters $(\mathrm{M}=4.05, \mathrm{SD}=1.032)$, and also to make reliable information on private health insurance companies available publicly $(\mathrm{M}=3.95$, $\mathrm{SD}=.910)$.

The outcome of the study revealed that the objective of the current insurance regulatory reforms in Ghana is to ensure safety and soundness of insurers; socio-economic development; and offer protection to consumers. When asked in an interview about the main objective of the current insurance regulatory framework, the personnel from the NHIA who participated in the interview revealed that the purpose of the reforms is to bring sanity into the insurance industry; promote best practices; mitigate industry associated risks, and to safeguard the interest of all stakeholders for socio-economic development. This result supports the public interest theory of regulation.

\subsection{Impact of Regulatory Reforms on Activities of Private Health Insurance Schemes}

The second objective of the study was to determine the impact of the current regulatory reforms on the activities of the private health insurance companies in Ghana. To achieve this objective, the participants were asked to indicate, on a scale of 1 to 5 , the impact of the current regulatory reforms on their activities, with 1 being strongly disagree; 2, disagree; 3 , neutral; 4, agree and 5, strongly agree. The results of the analysis are presented in Table 2 . 
Table 2. Mean and Standard Deviation of the Responses of the Participants on the Impact of the Current Regulatory Reforms on the Activities of the Private Health Insurance Schemes.

\begin{tabular}{lll}
\hline Regulatory Impact & Mean & Std. Dev. \\
\hline Regulatory reforms has increased public confidence in the insurance industry & 3.48 & 1.000 \\
Regulations limits the activities of business & 3.15 & 0.936 \\
Complying with regulations creates more cost burdens than benefits & 2.83 & 0.905 \\
Complying with regulations is time consuming & 2.87 & 1.112 \\
\hline
\end{tabular}

Source: Author's Fieldwork (2020).

The impact of the current insurance regulatory reforms on activities of the private health insurance companies in Ghana was evaluated in terms of negative and positive impacts. Among the positive impacts, the participants somewhat agreed that $(\mathrm{M}=3.48, \mathrm{SD}=1.00)$ the regulatory reforms has increased public confidence in the private health insurance industry. On the other hand, in terms of the negative impacts, the participants somewhat agreed that the regulatory measures have limited the activities of their business $(\mathrm{M}=3.15, \mathrm{SD}=.936)$. However, the participants disagreed that complying with the regulations has created more cost burdens than benefits $(\mathrm{M}=2.83, \mathrm{SD}=.905)$, and time consuming $(\mathrm{M}=2.87, \mathrm{SD}=1.112)$.

The interviews conducted among personnel of the National Health Insurance Authority, revealed that the current insurance regulatory reform has increased public confidence in the insurance industry. A participant from the NHIA commented:

"The regulatory reforms have increased public confidence. This is because the public knows which insurance company is licensed and which one's license is revoked or suspended, through publication. People are now aware of the regulation and calls in to inquire, complain or seek redress where necessary".

Another personnel of the institution who participated in the study commented:

"Yes, now more than ever, due to the proactiveness of the regulator to engage all stakeholders regularly. The open door policy has built confidence since all reports can be made directly to the regulator".

\subsection{Observations and Deductions Made}

The study was to determine how the current regulatory reforms in the insurance industry in Ghana impact on the insurance business. The study specifically sought to assess the regulatory measures of the current regulatory reforms, determine the impact of the regulatory reforms on the activities of the insurance companies, find out the challenges of the regulatory reforms of the insurance industry, and the impact of the challenges on the overall satisfaction of the insurance companies. This section discusses the findings of the study.

\subsubsection{Regulatory Measures of the Current Regulatory Reforms}

The findings of the study revealed that the current regulatory reforms in the insurance sector in Ghana includes the NHIA having the power to grant licenses to the private health insurance companies; license intermediary companies, and withdraw authorization/license. Besides, the NHIA under the current regulatory reforms has the power to evaluate the quality of governance structure of the insurance schemes; evaluate the quality of management structure of insurance companies; evaluate the performance of the governing body of the insurance companies, and evaluate the performance of the management team of insurance companies. The reform has also given NHIA the power to examine the books and the records of private health insurance companies; require private health insurance companies to maintain acceptable financial records; evaluate the quality of the private health insurance companies' assets, and approve products of private health insurance companies. The NHIA has also been given the power to educate consumers on insurance matters and also make information on private health insurance companies available to the public.

The results from the interview of personnel of the NHIA revealed that under the current insurance regulatory reforms in Ghana, private health insurance companies are to maintain a minimum capital adequacy ratio of $150 \%$ and have a $10 \%$ deposit of 5.5 million at the bank. They are also to ensure the no premium no policy cover. These results of the study seem to agree with the findings of Klein [27]. A study of insurance regulations measures conducted by Klein [28] in the United States found that the regulators were to have extensive insurance database and computer network that connects all insurance departments; analyses and informs regulators on insurers' financial condition; coordinates examinations and regulatory actions regarding troubled companies; establishes and certifies states' compliance with minimum financial regulation standards; offers financial, reinsurance, actuarial, legal, computer, and economic expertise to insurance departments.

Klein in Principles for insurance regulation: An evaluation of current practices and potential reforms [28] is of the view that the rationale for insurance regulatory framework, especially at the occurrence of market failures, is centered on the promotion or restoration of economic efficiency.

\subsubsection{Impact of Regulatory Reforms on Activities of Insurance Companies}

The findings of the study revealed that the current insurance regulatory reforms have increased public confidence in the private health insurance companies. The personnel from the NHIA who participated in the study explained that the reason 
why public confidence in private health insurance schemes has increased is that the public now knows which insurance company is licensed and which ones are not or suspended, through regular publication. Consumers are now aware of the regulation, and so they regularly inquire, complain and seek redress when necessary.

\section{Conclusion}

This study is to examine the current private health insurance industry's regulatory framework and its impact on insurance in Ghana. This is motivated by the lack of empirical studies on how the current insurance regulatory framework in Ghana impact on the performance of the private health insurance industry. The study used primary data which comprised of 60 employees in management positions in the private health insurance companies in Ghana, and 5 personnel from the National Health Insurance Authority, the regulator. The employees of the National Health Insurance Authority were selected using purposive sampling technique, while those of the private health insurance companies were chosen using simple random sampling technique. The study used ordinary simple linear regression analysis to determine the impact of regulatory challenges on insurance companies' overall satisfaction with the regulatory reforms in Ghana.

It can be concluded based on the findings of the study that the main reason for the current insurance regulatory framework in Ghana is to ensure safety and soundness of insurers; offer protection to consumers; sanitize the insurance industry; promote best practices; mitigate industry associated risks, and to safeguard the interest of all stakeholders for socio-economic development.

It is also deduced that the current insurance regulatory measures are established to manage the systemic risks and market failures. The systemic risk of the insurance industry has prompted the regulators to enforce regulatory measures such as the minimum capital requirement and the no premium no cover policy. Also, market failures have incited the regulators to ensure that insurance companies operate within the regulatory framework.

The result has again established that the current insurance regulatory framework has both positive and negative impact on insurance companies' activities in Ghana. In terms of the positive impact, it has established that the regulatory reform has increased public confidence in insurance companies in Ghana. Concerning the negative impact, the study has confirmed that the current insurance regulatory framework has limited the business opportunities of the insurance companies.

From the findings, it can be concluded that insurance companies in Ghana are confronted with several challenges as a result of the regulatory framework. These are logistical, education and training, human resource, legislative, and economical or financial challenges.

The results of the ordinary simple linear regression analysis give evidence to conclude that the regulatory challenges faced by insurance schemes in Ghana have a significant negative impact on insurance companies' overall satisfaction with the current insurance regulatory framework.

Lastly, from the findings of the study, the theory for this study - the public interest theory of regulation - is supported. It can be concluded that the current insurance regulatory framework promotes the public interest by making sure that the public is protected from any economic mishaps of the insurance companies and to ensure the public has transactions with insurance companies that are in good standing.

\section{Recommendations}

\subsection{Provision of Logistical Support}

It is recommended that the government, through the regulatory authority, the NHIA, supports the private health insurers in the acquisition of logistics, to enable smooth implementation of the regulatory framework. This can be done by providing the private insurers some tax exemptions. Thus, the private health insurers will get enough capital through these exemptions and considerations to enable them secure the necessary logistics for their operations and compliance to regulations.

\subsection{Provision of Education / Training and Technical Personnel}

It is recommended that the NHIA trains insurance companies intermittently on regulatory guidelines and other relating enactments to enable them provide better and quality service to the public. Additionally, NHIA as well as the private health insurers, should help provide training and education to employees by offering these individuals scholarships and bursaries to study insurance courses that will help in the development of the insurance industry in Ghana. They should also regularly educate the public on the benefits of insurance to help improve the low level of market penetration of insurance in Ghana.

\subsection{Provision of Economic or Financial Support}

It is also recommended that the government, through the NHIA, design and model regulations in a way that will aid in the management of risk as well as enhance the performance of insurers in Ghana. For instance, the minimum capital requirement should be prescribed per risk levels the insurance companies are exposed to. This will bring fairness to the insurance system. Also the impact of regulation on businesses should be considered when stringent regulatory procedures are being imposed. As much as possible, regulations should be made flexible to allow insurers to take on new initiatives and introduce more products that will aid in their economic growth.

Pricing of health insurance premiums and benefits packages as well as care costs or tariffs across health facilities should be standardized as this would bring costing and expenses to much appreciable levels. 


\section{Acknowledgements}

The authors would like to acknowledge all those who assisted in the design and conduct of the research from the respective departments and universities of the authors.

\section{References}

[1] Sebiyam, M. (2005). The impact of Insurance on Transport Business in Ghana: A case Study in Sunyani Municipality. Sunyani Polytechnic, Sunyani, Ghana.

[2] Rejda, G. E. (2005). Risk management and insurance. Person Education Inc, 13.

[3] Anderson, J. F., \& Brown, R. L. (2005). Risk and insurance. education and examination committee of the society actuaries.

[4] Holyoake, J., \& Weipers, N. (1999). Insurance. CIB Publishing, Canterbury.

[5] Kirkpatrick, J. (2018). Making the case for competition in policymaking-lessons from CMA advocacy 2014-2018. European Competition Journal, 14 (1), 152-173.

[6] National Insurance Commission Annual Report, 2009.

[7] Business and Financial Times (2010), July Edition of the Ghanaian Newspaper.

[8] Hutter, B. \& Power, M. (2012). Private health insurance: implications for developing countries. Bull World Health Organ.; 83: 127-134.

[9] White, M. (2013). The manipulation of choice: Ethics and libertarian paternalism. Springer.

[10] OECD, O. (2004). The OECD principles of corporate governance. Contaduría y Administración, (216).

[11] Thomson, S. (2014). Health system responses to financial pressures in Ireland. Retrieved on July 30, 2021 from http://zbw.eu/econis-archiv/bitstream/11159/42/1/821868292_H ealth-system-responses-to-financial-pressures-in-Ireland.pdf.

[12] Kofman, E., \& Raghuram, P. (2006). Gender and global labour migrations: Incorporating skilled workers. Antipode, 38 (2), 282-303.

[13] Sekhri, N., \& Savedoff, W. (2005). Private health insurance: implications for developing countries. Bulletin of the World Health Organization, 83, 127-134.
[14] Spaan, E., Mathijssen, J., Tromp, N., McBain, F., Have, A. T., \& Baltussen, R. (2012). The impact of health insurance in Africa and Asia: a systematic review. Bulletin of the World Health Organization, 90, 685-692.

[15] Nagar, (2005) Chartered Insurance Institute (CII) Coursebook, Insurance Law, CII learning solutions, pp 7/2-7/13, 11/1 - 11/6.

[16] Viscusi, WK, JM Vernon, and JE Harrington, Jr. Economics of Regulation and Antitrust, 2nd ed. Cambridge MA: MIT Press, 1995.

[17] Hertog, P. D. (2000). Knowledge-intensive business services as co-producers of innovation. International journal of innovation management, 4 (04), 491-528.

[18] Stigler, G. (1971). The theory of economic regulation. Bell Journal of Economics and Management Science, 2 (1), 3-21.

[19] Posner, R. (1974). Theories of economic regulation. Bell Journal of Economics and Management Science, 5 (2), 335-358.

[20] Muller, C. (1990). Health care and gender. Russell Sage Foundation.

[21] Pfeffer, A. Z., Feldman, D. J., Feibel, C., Frank, J. A., Cohen, M., Berger, S.,... \& Greenberg, S. S. (1956). A treatment program for the alcoholic in industry. Journal of the American Medical Association, 161 (9), 827-836.

[22] Creswell, J. W., Plano Clark, V. L., Gutmann, M., \& Hanson, W. (2003). Advanced mixed methods research designs. In Tashakkori, A. \& Teddlie, C. (Eds.), Handbook of mixed methods in social and behavioral research (pp. 209-240). Thousand Oaks, CA: Sage.

[23] Morse, J. M. (1991). Approaches to qualitative-quantitative methodological triangulation. Nursing Research, 40 (1): 120-123.

[24] Patton, M. Q. (1990). Qualitative Evaluation and Research Methods (2nd ed.). Newbury Park, CA: Sage Publications, Inc.

[25] Banerjee, A. \& Chaudhury, S. (2010). Statistics without tears: Populations and samples. Ind Psychiatry J. 19 (1), 60-65.

[26] Nhis.gov (2020). Private health insurance scheme. Retrieved from http://www.nhis.gov.gh/phis.aspx

[27] Klein, R. W. (1995). Insurance Regulation in Transition. The Journal of Risk and Insurance, 62 (3), 363-404.

[28] Klein, R. W. (2012). Principles for insurance regulation: An evaluation of current practices and potential reforms. The Geneva Papers, 37, 175-199. 